\title{
An epigenetic, transgenerational model of increased mental health disorders in children, adolescents and young adults
}

\author{
Anthony P. Monaco ${ }^{1}$
}

Received: 5 April 2020 / Accepted: 8 September 2020 / Published online: 18 September 2020

(c) The Author(s) 2020. This article is published with open access

\begin{abstract}
Prevalence rates of mental health disorders in children and adolescents have increased two to threefold from the 1990s to 2016. Some increase in prevalence may stem from changing environmental conditions in the current generation which interact with genes and inherited genetic variants. Current measured genetic variant effects do not explain fully the familial clustering and high heritability estimates in the population. Another model considers environmental conditions shifting in the previous generation, which altered brain circuits epigenetically and were transmitted to offspring via non-DNA-based mechanisms (intergenerational and transgenerational effects). Parental substance use, poor diet and obesity are environmental factors with known epigenetic intergenerational and transgenerational effects, that regulate set points in brain pathways integrating sensory-motor, reward and feeding behaviors. Using summary statistics for eleven neuropsychiatric and three metabolic disorders from 128,989 families, an epigenetic effect explains more of the estimated heritability when a portion of parental environmental effects are transmitted to offspring alongside additive genetic variance.
\end{abstract}

\section{Introduction}

There has been a two to three-fold rise in prevalence rates for several mental health disorders (MHD) in U.S. children and adolescents over the past twenty years (Fig. 1a, [2000-2017 contiguous data from the Centers for Disease Control, National Health and Nutrition Examination Surveys (NHANES) and National Survey on Drug Use and Health; pre-2000 data points referenced] [1-6]. There has also been a markedly increased rate of suicide in the U.S. since 2008 among the 10-24 year olds, and growth in suicidal ideation or attempts, self-harming behavior, and onset of major mood disorders with acute presentation [7-9].

Proposed contributing factors to increased rates of MHD in children and young adults include adverse childhood experiences, trauma, identity discrimination, financial

Supplementary information The online version of this article (https:// doi.org/10.1038/s41431-020-00726-4) contains supplementary material, which is available to authorized users.

Anthony P. Monaco

anthony.monaco@tufts.edu

1 Office of the President, Ballou Hall, Tufts University, Medford, MA 02155, USA burden, social media/screen time, substance use, academic/ career stress, and other environmental factors and their interaction with individual genetic susceptibility [9, 10]. Population level studies on early childhood screen time and adolescent use of smartphones and social media, showed only weak or no association with decreased mental wellbeing or increased MHD [11].

It is challenging to test plausible causal hypotheses for the increased prevalence of MHD. This paper will discuss potential epidemiological, genetic, environmental and epigenetic mechanisms, including parental transmission to offspring of shared and unique environmental effects. Human genetic studies of common, complex diseases such as MHD have implicated thousands of genetic variants by genome-wide association and sequencing analysis. Despite adequately powered clinical cohorts, only small increments in risk are generated by individual genetic variants and the overall polygenic effect explains only a fraction of the familial clustering and heritability estimates in the population [10, 12]. Geneticists have turned to whole genome sequencing (WGS) efforts and other approaches to explain the remaining heritability (Supplementary material) [13]. Unknown rare variants may be contributing to disease risk but initial WGS studies of disease cohorts revealed small numbers of functional rare variants with larger cohorts needed [14]. 
a: Prevalence Rates (\%) for Obesity, ADHD, ASD and Major Depression in Youth 1970-2016 b. Substance Use (\%) in 12th Grade Youth 1976-2018

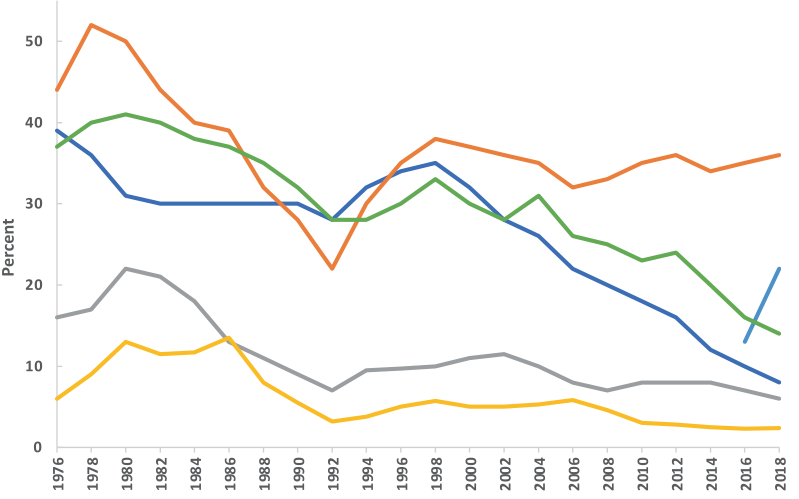

Fig. 1 Prevalence Rates for Obesity, ADHD, ASD, Major Depression and Substance Use in Youth. a Prevalence Rates for Obesity, ADHD, ASD and Major Depression in Youth 1970-2016. Obesity rates from NCHS, National Health Examination Survey III (ages 12-17) and National Health and Nutrition Examination Surveys (NHANES) I-III, and NHANES 1999-2000, 2001-2002, 2003-2004, 2005-2006, 2007-20008, 2009-2010, 2011-2012, and 2013-2014 (https://www.niddk.nih.gov/health-information/health-statistics/overw eight-obesity). Autism spectrum disorder (ASD) rates for 1970s-80s and 1980s-1990s [18]. ASD rates for 2000-2014 were from CDC (https://www.cdc.gov/ncbddd/autism/data.html). The rates for Attention Deficit Hyperactivity Disorder (ADHD) from 1998-2016 were from CDC (https://www.cdc.gov/ncbddd/adhd/timeline.html) National Health Interview Survey (NHIS) annual report 3-17 years of age. The

Intergenerational and transgenerational effects via emerging epigenetic mechanisms could also contribute to heritability estimates given the strong behavioral and metabolic effects in rodent models across multiple generations for environmental exposures to stress, toxicants, substances of misuse and obesogenic diet [13, 15]. Heritability estimates for human neuropsychiatric and metabolic disorders will be modeled for transmission of parental environmental effects to offspring alongside additive genetic effects. Environmental factors such as substance use and misuse, poor diet, and obesity will be implicated, as well as convergent brain mechanisms for long-term epigenetic dysregulation, which in rodent models, are transmitted to offspring through intergenerational and transgenerational mechanisms affecting behavioral and metabolic traits.

\section{Epidemiology}

Epidemiologic data for U.S. children and adolescents were reviewed over the past fifty years to understand when the increased rates of MHD diagnoses began. Trend lines for rates of past-year major depressive episode (12-17 years old), obesity (12-17 years old), and parent survey-reported

rates for ADHD for 1972 and 1978 were taken from school community teacher surveys $[16,17]$. The rates for past-year major depression episode (MDE) DSM-IV criteria are from the 12-17 age group as analyzed by Weinberger et al., 1999 with data from National Survey on Drug Use and Health (NSDUH) [6]. Depression rates for 1970 and 1992 [1]. b Substance Use in 12th Grade Youth 1976-2018. Percentage substance use for 12th graders for nicotine by smoking (30-day past use), cocaine (including crack, annual past use) and amphetamine (including Ritalin and Adderall, annual past use), marijuana (annual past use), alcohol bingeing ( $\%$ who had $5+$ drinks in a row at least once in the past 2 weeks) and vaping THC and nicotine (30-day past use) [58]. For cocaine, amphetamine and marijuana, 30-day past use data were only available from 1991 onwards [58].

diagnoses (3-17 years old) of Attention Deficit Hyperactivity Disorder (ADHD) and Autism Spectrum Disorder (ASD) are shown in Fig. 1a. Until the mid-1990s, the rates for major depressive episode in adolescents and ADHD in children and adolescents were 4-6\%, with ASD in children and adolescents below 0.5\% [16-18]. They all trended upwards by 2000 , with depression reaching $13 \%$ of adolescents in 2016, and in the 3-17-year-old age group, ADHD was $9.4 \%$ and ASD was $1.7 \%$. Anxiety disorders were complex to chart over this time period given changes in diagnostic and subtype criteria. However, rates for anxiety disorders, across all age groups, were relatively stable from 1970-1992 [1] with increases seen across many subtypes from 2000-2016 [19-21].

It is difficult to quantify the extent to which increased rates of MHD in children and adolescents were based on (1) steady rises in participation in mental health services due to decreased stigma, (2) increased awareness and better treatments by clinicians, (3) changes in diagnostic criteria, or (4) an underlying increase in incidence and prevalence. Longitudinal and cross-sectional studies have attempted to discern the differences, but the situation is complex $[9,22,23]$. Although the diagnostic landscape for MHD has changed, the significantly increased rate of acute presentation and 
suicide in adolescents and young adults over the last 10-15 years in the U.S. should not be affected by the first three factors (unless there is a treatment effect on suicide; not all countries have seen increased suicide rates) [7]. Some portion of these striking increases in MHD diagnoses in the U.S. over twenty years could be due to a true increase in incidence and prevalence rates. Recent age:cohort:period analyses of mood disorder rates and suicide-related outcomes in U.S. adolescents and young adults showed a strong cohort effect for those born in the late 1990s who are college-age today [9].

\section{Mechanisms for increased mental health disorders in children and adolescents}

Possible mechanisms for increased MHD include changing environmental conditions, affecting the fetus in utero (intergenerational maternal effects) or early in post-natal life (intragenerational effects on offspring). In animal paradigms, maternal stress or toxic exposures in utero epigenetically altered the fetal genome to change long-term gene expression thereby influencing health and behavior in the progeny [24].

A second intergenerational epigenetic mechanism is bacterial "microbiome" populations, most notably in the intestinal and urogenital tracts. In humans, an unhealthy maternal microbiome has been shown to increase pre-term births, and intestinal flora have been implicated in neurological and metabolic disorders [25-27]. In mouse models, maternal stress effects on vaginal microbiota influenced the health and behavior of male progeny with gene expression changes in the hypothalamus [28]. Also, a poor maternal diet led to gut microbiome changes in male mouse offspring, inducing social deficits which were restored via reintroduction of a commensal bacterial strain [29].

A third potential mechanism is long-term, epigenetic changes that influence health and behavior across multiple generations (intergenerational and transgenerational effects defined by number of generations affected) [15, 24, 30, 31]. There are many rodent models of stress, rewarding foods and substances of misuse which can alter synaptic plasticity in specific brain circuits and influence the health and behavior of the next generation progeny ( $\mathrm{F} 1$ for father exposed) and remarkably, the third-generation (F2) [15, 3238]. In mice, the transmission of the negative consequences of a poor diet in males were due to changes in the content sperm small non-coding RNAs (ncRNAs) including microRNA (miRNA) and transfer RNA fragments [39]. Recent evidence using a paternal transgenerational stress model in mice, showed that small ncRNAs, specifically miRNA ratios in sperm, provided the epigenetic information to influence progeny behavior [40]. Changes in sperm
miRNAs found in mouse stress models were correlated with early life stress in humans [41].

miRNAs are small single-stranded regulatory ncRNAs (21-25 nucleotides) involved in controlling protein levels by binding to the 3'-untranslated region of messenger RNAs and enhancing their decay before translation can initiate and also by direct ribosomal translation inhibition [42]. They are found in multiple cellular compartments and released upon stress via exosomes (along with other ncRNAs and cell-specific protein and lipid cargos) thereby influencing cell-cell communication [43]. miRNAs are stable over time and along with other ncRNAs, are candidates for enduring regulators of developmental, regenerative, metabolic, brain, and infectious states in response to changing environmental conditions. miRNAs are enriched in the epididymis and secreted by luminal principal cells via epididymosomes with other ncRNAs and protein cargoes, influencing the luminal environment in anatomically distinct compartments. Epididymosome cargoes together with other epigenetic mechanisms in developing spermatozoa, could influence genome regulation in the zygote and developing fetus [44, 45]. There is also evidence for exosome vesicles secreted by the oviduct and embryo, opening up novel lines of communication and regulation in the gametes-embryo-oviduct environment [46].

Current studies are aimed at understanding mechanisms in vertebrates by which environmental changes are integrated over time to generate deviations in gamete epigenetic marks. A central question is whether the nervous system provides the sensory integration to signal changes to gametes via neuronal, exosome or hormonal pathways, or the cellular environment of gamete development is able to sense and integrate environmental factors directly. In the worm C. elegans, a detailed RNA-based mechanism was shown for neuronal activity directly effecting germline ncRNA content and the behavior of the next generation [47]. Recently, direct evidence for transmission of miRNAs was demonstrated from male mouse brains to the germline and one-third of F1 embryos [48]. In addition to ncRNA mechanisms, there are examples of stable transmission of chromatin condensation, histone modifications, and DNAmethylation which are transmitted to offspring via gametes, which have been reviewed extensively [24, 30, 35].

In humans, there is evidence for transgenerational effects of trauma, adverse childhood experiences and PostTraumatic Stress Disorder [49, 50]. Children of Holocaust survivors, for example, experienced epigenetic changes within the hypothalamic-pituitary-adrenal axis [51]. The phenomenon of transgenerational inheritance has also been attributed to famine undernutrition in the Netherlands in WWII. There were significant increases in adiposity and other health issues not only in the second generation but in grandchildren of those affected by the famine [52]. Swedish 
studies also provided evidence for rapid changes in food supply having a possible transgenerational effect from maternal grandmothers through their sons to poor cardiovascular outcomes in maternal granddaughters [53]. Analysis of Swedish adoption registries revealed a biological parental environment effect transmitted to offspring with alcohol use disorder alongside genetic and parental rearing environment effects [54]. Using the ALSPAC cohort, paternal early age cigarette smoking was shown to significantly increased body mass in adult children, which was stronger for male offspring [31]. There is evidence for transgenerational effects in domesticated farm animals and birds from parental exposures to environmental toxicants, nutrients and infectious agents $[55,56]$.

\section{Potential environmental factors for intergenerational and transgenerational effects}

Substance use and misuse (including alcohol and smoking), poor diet, and obesity are three environmental conditions with potential long-term epigenetic and transgenerational effects which could have influenced rates of MHD in the current generation. These three factors were already implicated as major environmental contributors to decreased life expectancy in the U.S. from 2015 to 2017. The highest specific contributions were from drug overdose, suicide, and alcohol- and obesity-driven organ system disease, with increases dating back to the 1990s [8, 57]. The strongest environmental contributors to decreased morbidity and mortality in the U.S. population may also have contributed an intergenerational or transgenerational effect to health outcomes in the next generation.

Nicotine, caffeine, stimulants, and marijuana were all used frequently in the population during the 1970-80s (Fig. 1b) [58, 59]. Nicotine use declined nearly fourfold between the late 1970s, when $30-40 \%$ of youth and adult populations reported use, to $<10 \%$ in 2018 [58, 59]. In the 1970-80s there was a very large increase in high school students and young adults in the U.S. using marijuana, stimulants and binge-drinking alcohol (Fig. 1b) [58, 59]. Cocaine, amphetamine(s), and methylphenidate were taken recreationally or for performance-enhancement, in a significant portion of the population during the 10-year period from 1976 to 1986. Caffeine intake was high throughout the past 50 years but consumption of high sugar caffeinated soft drinks, particularly in children, increased dramatically in the $1970-80$ s to peak at the turn of the century $[60,61]$. Heroin was used less frequently during the 1970-80s, but significant increases in opioid addiction started after the introduction of long-acting prescription pain relievers in the 1990s with many users switching to heroin following prescription tightening habits, in combination with other substances like fentanyl, resulting in higher drug overdose deaths since 2000 [8, 58, 59, 62].

Heritability estimates for substance use disorders (SUD) have shown specific and pleiotropic genetic effects for all substances with cocaine and marijuana the strongest, modest levels for nicotine and alcohol, and lowest levels for caffeine [63]. Risk for SUD comprised contributions from both genetic variants (nicotinic acetylcholine receptor variants in SUD) and environmental influences (parental control, permissive environment for access). The environmental effects changed from childhood to adolescence, and indirect effects of gene-environment correlations are plausible where disorder-specific behaviors increased the environmental exposures, as seen in ADHD and SUD [63].

In addition to increased substance misuse, a second major societal trend involved dramatic changes to the U.S. food supply and lifestyle after the 1960s [60]. This comprised major rises in availability and consumption of ultraprocessed foods (rich in refined starch, sugar and additives), high sugar caffeinated soft drinks, alcohol, and other factors such as continued physical inactivity and sedentary lifestyle. In the 1980s, childhood obesity in the U. S. was $5 \%$, and rose rapidly to $20 \%$ today (NHANES, 3-17-year olds, Fig. 1a). Poor diet and obesity should be considered as correlated, but separable environmental conditions with both anatomical and temporal differences in potential brain effects. The increase in childhood and adolescent obesity (NHANES, Fig. 1a) and peak of substance use and misuse (Fig. 1b), occurred 15-20 years before the steady increases in MHD, providing adequate time for a transgenerational phenomenon to have occurred affecting this generation.

Changes in diet and accompanying obesity, in addition to high prevalence of substance misuse, may have had intergenerational and transgenerational effects, which are now manifesting themselves as new set points in brain circuits for highly regulated sensory, motor, reward and feeding systems. These new set points and relative sensitization of specific brain circuits could contribute epigenetically to increased risk for MHD. In rodent models of stress, obesogenic diet, and substance misuse (methamphetamine, cocaine, and opioids), miRNA levels have been shown to be dynamically regulated in the ventral basal ganglia, and in the methamphetamine model, corresponded to specific shared miRNA levels in circulating serum exosomes [6468].

Given their rewarding and possibly addictive nature, ultraprocessed, high glycemic index foods may have contributed to dysregulation of reward pathways in the basal ganglia to prefrontal cortex and limbic system [69]. There is convincing evidence that palatable foods, with high glycemic index, stimulate the same reward pathways in the 
Table 1 Residual heritability for five neuropsychiatric disorders.

\begin{tabular}{llllll}
\hline Disorder & ASD & ADHD & Bipolar disorder & Depression & Schizophrenia \\
\hline$H^{2}$ & 0.924 & 0.763 & 0.676 & 0.579 & 0.562 \\
$G_{A}$ measured & 0.37 & 0.30 & 0.25 & 0.21 & 0.27 \\
$\left(G_{S N P}+\mathrm{CNVs}\right)$ & $(0.17+0.2)$ & $(0.28+0.02)$ & $37 \%$ & $36 \%$ & $(0.23+0.04)$ \\
& $40 \%$ & $39.3 \%$ & & & $48 \%$ \\
Residual $H^{2}$ & 0.554 & 0.463 & 0.426 & 0.369 & 0.292 \\
& $60 \%$ & $60.7 \%$ & $63 \%$ & $63.7 \%$ & $52 \%$ \\
Estimated & 0.924 & 0.568 & 0.468 & 0.373 & 0.435 \\
$G$ effect & & $(0.468+0.1)$ & $(0.333+0.135)$ & $(0.192+0.181)$ & $(0.308+0.127)$ \\
{$\left[G_{A}\left(0.5 E_{P}\right)+0.5 E_{P}\right]$} & & $74.4 \%$ & $69.2 \%$ & $64.2 \%$ & $77.4 \%$ \\
Residual $H^{2}$ & 0 & 0.195 & 0.208 & 0.207 & 0.127 \\
& & $25.6 \%$ & $30.8 \%$ & $35.8 \%$ & $22.6 \%$ \\
\hline
\end{tabular}

Heritability $H^{2}$ [72], measured $G_{A}=G_{S N P}+\operatorname{CNVs}[10,14,73,74]$, Residual $H^{2}$, Estimated $G\left(\sigma_{G}^{2}\right)=$ $\left(G_{A}+0.5 E_{P}\right)$ effects (this paper) and Residual $H^{2}$ for five major psychiatric disorders. All $\%$ are for portion of $H^{2}$. basal ganglia as all of the substances of misuse in both humans and animal models [69, 70]. Substances of misuse, ultraprocessed high glycemic index foods and high sugar caffeinated drinks could have acted cooperatively to sensitize the cortico-striatal-limbic and cortico-striatal-thalamic pathways to further rounds of these environmental conditions, which are transmitted as new set points to the next generation.

\section{Test of the transgenerational model}

From genetic studies of common diseases with large cohort sizes, the genetic variance effect size of individual genomewide significant variants is small and the overall polygenic variation $\left(G_{A}\right)$ is also relatively small $(0.05-0.3)[10,71]$. When the effect size is measured across multiple large single-nucleotide polymorphism (SNP) genotyping studies for five common MHD, estimates of $G_{S N P}$ for schizophrenia (0.23), bipolar disorder (0.25), major depressive disorder (0.21), ASD (0.17), and ADHD (0.28) plus known CNV contributions, showed that only $36-48 \%$ of the heritability is explained by $G_{A}=G_{S N P}+$ CNVs (Table 1) [10, 14, 72-74].

In Supplementary material, the possible reasons for the remaining heritability are discussed including additional rare variants and possible intergenerational and transgenerational effects. If a portion of the parental shared environmental variance is contributing to a transgenerational effect, then a first approximation for broad-sense heritability $\left(H^{2}\right)$ can be estimated from the first-order direct genetic and environmental variances only:

$H^{2} \cong \frac{G_{A}+x E_{P}}{G_{A}+E_{P}+E_{O}} \cong \frac{G_{A}+x E_{P}}{G_{A}+E}$,

where $E=x E_{P}+(1-x) E_{P}+E_{O}=E_{P}+E_{F}+E_{S}+$ $E_{U}, 0<x<1$ and $E_{O}=$ offspring environmental, $\mathrm{E}_{P}=$ shared parental, $\mathrm{E}_{F}=$ shared familial, $\mathrm{E}_{S}=$ shared sibling,
$\mathrm{E}_{U}=$ unique environmental variances, $0<x<1$ (Supplementary material).

Empirical data from 40 million U.S. insurance claims for 149 common diseases was used to estimate liability-scale heritability and environmental variances in 481,657 unique individuals from 128,989 families where both parents and children were covered for at least 6 years [72]. To test the transgenerational model, eleven neuropsychiatric and three metabolic disorders where chosen from this large-scale study with high heritability estimates (avg. 0.60, range 0.422-0.924), comparable with most meta-analyses from either family or twin studies, with some variability. For these fourteen disorders, the average shared parental environmental effect $\left(E_{P}\right)$ is high $(0.27), 63 \%$ of the total environmental variance $(E)$, with autism being an outlier with no shared parental environmental effect (Supplementary material). In addition, for 21 neuropsychiatric disorderpairs, the environmental correlations $\left(\overline{r_{e}}=0.39\right)$ were nearly as strong as the genetic correlations $\left(\overline{r_{g}}=0.5\right)$ with clear groupings of MHD reflected in the resulting nosology classification (Supplementary material) [72].

To test the transgenerational model, where $E_{P}$ would contribute some fraction of its variance effect to the total genetic variance $G$ along with additive genetic variance $G_{A}$, summary statistics for heritability $\left(H^{2}\right)$, environmental variance effects from couples $\left(E_{P}\right)$, siblings $\left(E_{S}\right)$ and unique environmental effects $\left(E_{U}\right)$ were selected from Wang et al, (2017) for eleven neuropsychiatric and three metabolic disorders [72]. For each disorder $G$ was calculated (Supplementary material) under four models of $x E_{P}$ contributing to the numerator in equation number 4 with $x=0.25,0.5,0.6$ or 0.667 .

A transgenerational model of $E_{P}$ contributing some fraction of its effect to total genetic variance $G$, decreases the contribution of estimated additive genetic variance $G_{A}$ to heritability. The $0.5 E_{P}$ model showed $G_{A} \geq x E_{P}$ in its contribution to $G$ for most disorders, and estimated $G_{A}$ 
Fig. 2 Graph of $0.5 E p$ transmission effect for 11 neuropsychiatric disorders and 3 metabolic disorders by decreasing heritability estimate. Shows the effects of adding $0.5 E_{P}$ into the total genetic variance $G$ and calculated additive genetic variance $\left(G_{A}\right)$ using estimates for heritability $\left(H^{2}\right)$, shared parental environmental variance $\left(0.5 E_{P}\right)$ and total environmental variance $(E)$ by decreasing order of heritability for 11 neuropsychiatric disorders and 3 metabolic disorders [72].

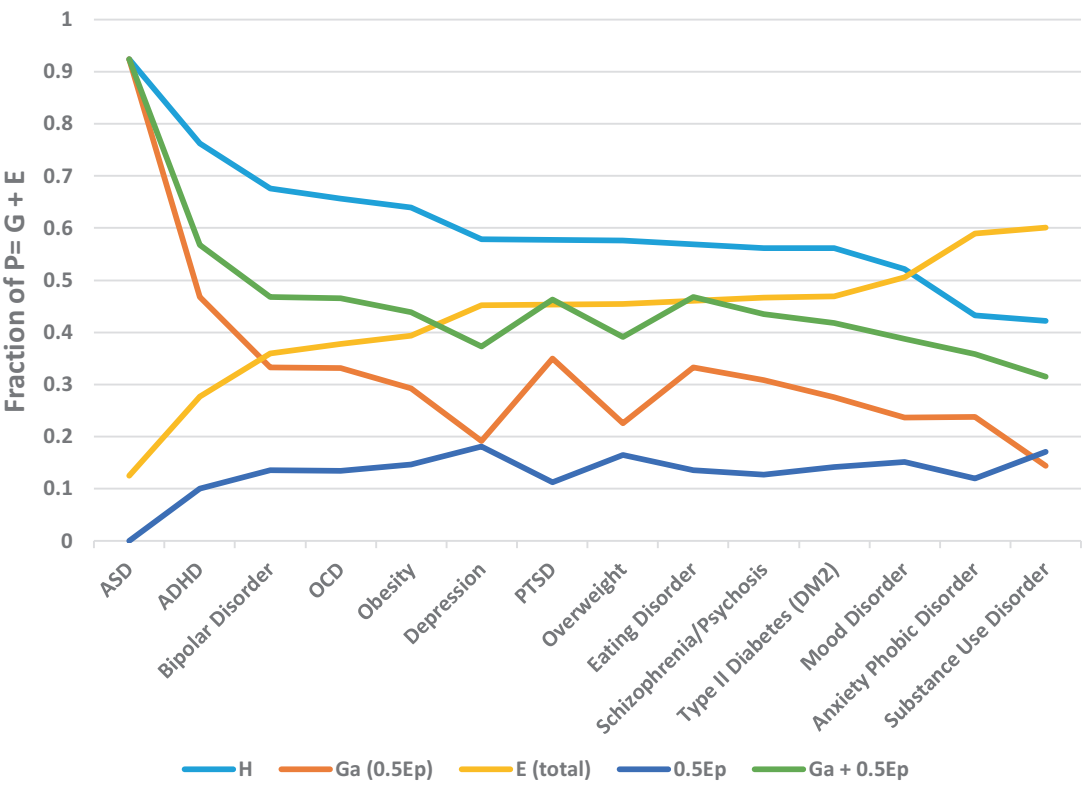

variants. Figure 2 presents the relationship of $G_{A}$ and $0.5 E_{P}$ in the transgenerational model by disorder heritability from highest to lowest. The additive effects of $G_{A}$ and $x E_{P}$ to $G$ do significantly close the gap in the remaining heritability, but do not explain it fully.

Table 1 shows estimated liability-scale heritability estimates for five neuropsychiatric disorders with $H^{2}$ above 0.56 [72] and remaining heritability after accounting for measured $G_{A}=G_{S N P}$ from the largest metaanalysis [10] and percentage of CNVs contributing to the disorder [14, 73, 74]. It also shows $G \sim\left(G_{A}+0.5 E_{P}\right)$ calculated using summary statistics for $H^{2}, E$, and $E_{P}$ [72] in heritability equation number (1). This model shows a good fit with measured genetic effects of $G_{A}$ from $G_{S N P}$, rare variants and CNVs. Excluding autism as an outlier given the low contribution of total environmental variance $(E)$ (and specifically $E_{P}$ ), the other MHD show about $0.127-0.208(22-36 \%)$ of the heritability not accounted for by this hybrid model. In the traditional model, measured $G_{A}$ explains $36-48 \%$ of $H^{2}$, where the proposed transgenerational hybrid model $\left(G_{A}+0.5 E_{P}\right)$, explains $64-77 \%$ of $H^{2}$. The remainder may be explained by variation in phenotypic trait diagnoses, assortative mating, unobserved rare variants and second-order effects such as genetic epistasis and gene-environment interactions and covariances.

Analysis of variance of large empirical family datasets such as Wang et al. [72] under a genetic and transgenerational hybrid model would predict a better fit to the data if the shared parental environmental effects are biologically contributing to heritability estimates. It would also estimate more accurately $G_{A}, E_{P}$ and $E_{U}$ variance effects on broad-sense heritability than these arithmetic values aligned with current $G_{S N P}+\mathrm{CNV}$ effects from genetic association and sequencing data with room for additional genetic effects from WGS discovery of rare 
models might predict being constrained by $H^{2}$ calculated under the traditional narrow-sense heritability model in Wang et al. [72].

\section{Conclusion}

The effects of dietary and life-style changes in the 1970-80s initiated an obesity epidemic still being felt today. Daily consumption of poor diet, and high prevalence of nicotine, caffeine, marijuana, alcohol, and stimulant drugs in the 1970-80s hypothetically produced long-term changes to the reward and fronto-striatal pathways in the brain in a significant portion of the population. The chronic effects of basal ganglia dysregulation altered sensitization for reward and stress in the brain, with concomitant changes in gamete epigenetic marks, influencing prevalence rates for MHD in youth from the late 1990s until the present day. A intergenerational and transgenerational model (Fig. 3) for parental environmental effects working through an epigenetic code in gametes (ncRNAs and other mechanisms) in combination with additive genetic variance from DNA variants, could explain some of the remaining heritability from human genetic studies.

If this mechanism is contributing, then the next generation may continue to experience high rates of MHD given the continued rise in youth and adult obesity, and substance use and misuse (especially the recent upsurge of vaping nicotine and THC, Fig. $1 \mathrm{~b}$ and opioid addiction since 2000) [58]. The model predicts that the brain-gastrointestinal-urogenital axis may be essential to sense shifting environmental conditions, modulate behavior through specific circuits in the brain, and transmit epigenetic signals to the next generation. Recent longitudinal analysis in Denmark of MHD with onset of medical conditions found the strongest correlations (mean hazard risks of 3.62) for urogenital conditions and eating disorders, and strong correlations with circulatory, gastrointestinal and specific neurological disorders such as epilepsy and Parkinson's [75].

Epigenetic intergenerational and transgenerational changes are reversible, and studies are needed to explore both the effect of prevention of exposures in parents, and interventions in offspring at risk for mental health and correlated health disorders.

Acknowledgements Thank you to the many colleagues at Tufts and further afield who offered vital suggestions to the manuscript.

\section{Compliance with ethical standards}

Conflict of interest The authors declare that they have no conflict of interest.
Publisher's note Springer Nature remains neutral with regard to jurisdictional claims in published maps and institutional affiliations.

Open Access This article is licensed under a Creative Commons Attribution 4.0 International License, which permits use, sharing, adaptation, distribution and reproduction in any medium or format, as long as you give appropriate credit to the original author(s) and the source, provide a link to the Creative Commons license, and indicate if changes were made. The images or other third party material in this article are included in the article's Creative Commons license, unless indicated otherwise in a credit line to the material. If material is not included in the article's Creative Commons license and your intended use is not permitted by statutory regulation or exceeds the permitted use, you will need to obtain permission directly from the copyright holder. To view a copy of this license, visit http://creativecommons. org/licenses/by/4.0/.

\section{References}

1. Murphy JM, Horton NJ, Laird NM, Monson RR, Sobol AM, Leighton AH. Anxiety and depression: a 40-year perspective on relationships regarding prevalence, distribution, and comorbidity. Acta Psychiatr Scand. 2004;109:355-75.

2. Compton WM, Conway KP, Stinson FS, Grant BF. Changes in the prevalence of major depression and comorbid substance use disorders in the United States between 1991-1992 and 2001-2002. Am J Psychiatry 2006;163:2141-7.

3. Merikangas KR, He JP, Burstein M, Swanson SA, Avenevoli S, Cui L, et al. Lifetime prevalence of mental disorders in U.S. adolescents: results from the National Comorbidity Survey Replication-Adolescent Supplement (NCS-A). J Am Acad Child Adolesc Psychiatry. 2010;49:980-9.

4. Collishaw S. Annual research review: Secular trends in child and adolescent mental health. J Child Psychol Psychiatry. 2015;56:370-93.

5. Mojtabai R, Olfson M, Han B. National trends in the prevalence and treatment of depression in adolescents and young adults. Pediatrics. 2016;138:1-10.

6. Weinberger AH, Gbedemah M, Martinez AM, Nash D, Galea S, Goodwin RD. Trends in depression prevalence in the USA from 2005 to 2015: widening disparities in vulnerable groups. Psychol Med. 2018;48:1308-15.

7. Curtin S, Heron M. Death rates due to suicide and homicide among persons aged 10-24: United States, 2000-2017. NCHS data brief. 2019:1-8.

8. Woolf SH, Schoomaker H. Life expectancy and mortality rates in the United States, 1959-2017. JAMA. 2019;322:1996-2016.

9. Twenge JM, Cooper AB, Joiner TE, Duffy ME, Binau SG. Age, period, and cohort trends in mood disorder indicators and suiciderelated outcomes in a nationally representative dataset, 20052017. J Abnorm Psychol. 2019;128:185-99.

10. Lee SH, Ripke S, Neale BM, Faraone SV, Purcell SM, Perlis RH, et al. Genetic relationship between five psychiatric disorders estimated from genome-wide SNPs. Nat Genet. 2013;45:984-+.

11. Orben A. Teenagers, screens and social media: a narrative review of reviews and key studies. Soc Psychiatry Psychiatr Epidemiol. 2020;55:407-414.

12. Nolte IM, van der Most PJ, Alizadeh BZ, de Bakker PI, Boezen HM, Bruinenberg M, et al. Missing heritability: is the gap closing? An analysis of 32 complex traits in the Lifelines Cohort Study. Eur J Hum Genet. 2017;25:877-85.

13. Eichler EE, Flint J, Gibson G, Kong A, Leal SM, Moore JH, et al. Missing heritability and strategies for finding the underlying causes of complex disease. Nat Rev Genet. 2010;11:446-50. 
14. Consortium UK, Walter K, Min JL, Huang J, Crooks L, Memari $\mathrm{Y}$, et al. The UK10K project identifies rare variants in health and disease. Nature. 2015;526:82-90.

15. Schaefer $\mathrm{S}$, Nadeau JH. The genetics of epigenetic inheritance: modes, molecules, and mechanisms. Q Rev. Biol. 2015;90:381-415.

16. Miller RGJ, Palkes HS, Stewart MA. Hyperactive children in suburban elementary schools. Child Psychiatry Hum Dev. 1973;4:121-7.

17. Lambert NM, Sandoval J, Sassone D. Prevalence of hyperactivity in elementary school children as a function of social system definers. Am J Orthopsychiatry. 1978;48:446-63.

18. Fombonne E. The epidemiology of autism: a review. Psychol Med. 1999;29:769-86.

19. Kessler RC, Chiu WT, Demler O, Merikangas KR, Walters EE. Prevalence, severity, and comorbidity of 12-month DSM-IV disorders in the National Comorbidity Survey Replication. Arch Gen Psychiatry. 2005;62:617-27.

20. Kessler RC, Petukhova M, Sampson NA, Zaslavsky AM, Wittchen HU. Twelve-month and lifetime prevalence and lifetime morbid risk of anxiety and mood disorders in the United States. Int J Methods Psychiatr Res. 2012;21:169-84.

21. Ruscio AM, Hallion LS, Lim CCW, Aguilar-Gaxiola S, AlHamzawi A, Alonso J, et al. Cross-sectional comparison of the epidemiology of DSM-5 generalized anxiety disorder across the globe. JAMA Psychiatry. 2017;74:465-75.

22. Compton W, Conway KP, Stinson FS, Grant BG. Changes in the prevalence of major depression and comorbid substance use disorders in the United States between 1991-1992 and 2001-2002. Am J Psychiatry. 2006;163:2141-7.

23. Jorm AF, Patten SB, Brugha TS, Mojtabai R. Has increased provision of treatment reduced the prevalence of common mental disorders? Review of the evidence from four countries. World Psychiatry. 2017;16:90-9.

24. Bale TL. Epigenetic and transgenerational reprogramming of brain development. Nat Rev Neurosci. 2015;16:332-44.

25. Vinturache AE, Gyamfi-Bannerman C, Hwang J, Mysorekar IU, Jacobsson B, Preterm Birth International C. Maternal microbiome - a pathway to preterm birth. Semin Fetal Neonatal Med. 2016;21:94-9.

26. Bell JS, Spencer JI, Yates RL, Yee SA, Jacobs BM, DeLuca GC. Invited Review: from nose to gut - the role of the microbiome in neurological disease. Neuropathol Appl Neurobiol. 2019;45:195-215.

27. Sanna S, van Zuydam NR, Mahajan A, Kurilshikov A, Vich Vila A, Vosa U, et al. Causal relationships among the gut microbiome, short-chain fatty acids and metabolic diseases. Nat Genet. 2019;51:600-5.

28. Jasarevic E, Howard CD, Morrison K, Misic A, Weinkopff T, Scott $\mathrm{P}$, et al. The maternal vaginal microbiome partially mediates the effects of prenatal stress on offspring gut and hypothalamus. Nat Neurosci. 2018;21:1061-71.

29. Buffington SA, Di Prisco GV, Auchtung TA, Ajami NJ, Petrosino JF, Costa-Mattioli M. Microbial reconstitution reverses maternal diet-induced social and synaptic deficits in offspring. Cell. 2016;165:1762-75.

30. Cavalli G, Heard E. Advances in epigenetics link genetics to the environment and disease. Nature. 2019;571:489-99.

31. Golding J, Gregory S, Northstone K, Iles-Caven Y, Ellis G, Pembrey M. Investigating possible trans/intergenerational associations with obesity in young adults using an exposome approach. Front Genet. 2019;10:314.

32. Byrnes JJ, Johnson NL, Carini LM, Byrnes EM. Multigenerational effects of adolescent morphine exposure on dopamine D2 receptor function. Psychopharmacology. 2013;227:263-72.
33. Vassoler FM, White SL, Schmidt HD, Sadri-Vakili G, Pierce RC. Epigenetic inheritance of a cocaine-resistance phenotype. Nat Neurosci. 2013;16:42-7.

34. Szutorisz H, Egervari G, Sperry J, Carter JM, Hurd YL. Crossgenerational THC exposure alters the developmental sensitivity of ventral and dorsal striatal gene expression in male and female offspring. Neurotoxicol Teratol. 2016;58:107-14.

35. Post RM. Epigenetic basis of sensitization to stress, affective episodes, and stimulants: implications for illness progression and prevention. Bipolar Disord. 2016;18:315-24.

36. Wolstenholme JT, Drobna Z, Henriksen AD, Goldsby JA, Stevenson $\mathrm{R}$, Irvin JW, et al. Transgenerational bisphenol A causes deficits in social recognition and alters postsynaptic density genes in mice. Endocrinology. 2019;160:1854-67.

37. McCarthy DM, Morgan TJ Jr., Lowe SE, Williamson MJ, Spencer TJ, Biederman J, et al. Nicotine exposure of male mice produces behavioral impairment in multiple generations of descendants. PLoS Biol. 2018;16:e2006497.

38. Saavedra-Rodriguez L, Feig LA. Chronic social instability induces anxiety and defective social interactions across generations. Biol Psychiatry. 2013;73:44-53.

39. Bodden C, Hannan AJ, Reichelt AC. Diet-induced modification of the sperm epigenome programs metabolism and behavior. Trends Endocrinol Metab. 2019;31:131-149.

40. Gapp K, Jawaid A, Sarkies P, Bohacek J, Pelczar P, Prados J, et al. Implication of sperm RNAs in transgenerational inheritance of the effects of early trauma in mice. Nat Neurosci. 2014;17:667-9.

41. Dickson DA, Paulus JK, Mensah V, Lem J, Saavedra-Rodriguez L, Gentry A, et al. Reduced levels of miRNAs 449 and 34 in sperm of mice and men exposed to early life stress. Transl Psychiatry. 2018;8:101.

42. Gebert LFR, MacRae IJ. Regulation of microRNA function in animals. Nat Rev Mol Cell Biol. 2019;20:21-37.

43. Pegtel DM, Gould SJ. Exosomes. Annu Rev Biochem. 2019;88:487-514.

44. Zhou W, De Iuliis GN, Dun MD, Nixon B. Characteristics of the epididymal luminal environment responsible for sperm maturation and storage. Front Endocrinol. 2018;9:59.

45. Reilly JN, McLaughlin EA, Stanger SJ, Anderson AL, Hutcheon $\mathrm{K}$, Church K, et al. Characterisation of mouse epididymosomes reveals a complex profile of microRNAs and a potential mechanism for modification of the sperm epigenome. Sci Rep. 2016;6:31794.

46. Alminana C, Bauersachs S. Extracellular vesicles: Multi-signal messengers in the gametes/embryo-oviduct cross-talk. Theriogenology. 2020;150:59-69.

47. Posner R, Toker IA, Antonova O, Star E, Anava S, Azmon E, et al. Neuronal small RNAs control behavior transgenerationally. Cell 2019;177:1814-26 e15.

48. O'Brien EA, Ensbey KS, Day BW, Baldock PA, Barry G. Direct evidence for transport of RNA from the mouse brain to the germline and offspring. BMC Biol. 2020;18:45.

49. Le-Scherban F, Wang X, Boyle-Steed KH, Pachter LM. Intergenerational associations of parent adverse childhood experiences and child health outcomes. Pediatrics. 2018;141:1-9.

50. Suglia SF, Crookes DM, Kaplan R, Sotres-Alvarez D, Llabre MM, Van Horn L, et al. Intergenerational transmission of childhood adversity in parents and their children's BMI in the Hispanic Community Children's Health Study/Study of Latino Youth (HCHS/SOL Youth). J Psychosom Res. 2020;131:109956.

51. Yehuda R, Lehrner A, Bierer LM. The public reception of putative epigenetic mechanisms in the transgenerational effects of trauma. Environ Epigenet. 2018;4:dvy018. 
52. Veenendaal MV, Painter RC, de Rooij SR, Bossuyt PM, van der Post JA, Gluckman PD, et al. Transgenerational effects of prenatal exposure to the 1944-45 Dutch famine. BJOG. 2013;120:548-53.

53. Bygren L, Tinghög P, Carstensen J, Edvinsson S, Kaati G, Pembrey ME, et al. Change in paternal grandmothers' early food supply influenced cardiovascular mortality of the female grandchildren. BMC Genet. 2014;15:12.

54. Kendler KS, Ji J, Edwards AC, Ohlsson H, Sundquist J, Sundquist K. An extended Swedish national adoption study of alcohol use disorder. JAMA Psychiatry. 2015;72:211-8.

55. Guerrero-Bosagna C, Morisson M, Liaubet L, Rodenburg TB, de Haas EN, Kostal L, et al. Transgenerational epigenetic inheritance in birds. Environ Epigenet. 2018;4:dvy008.

56. Thompson RP, Nilsson E, Skinner MK. Environmental epigenetics and epigenetic inheritance in domestic farm animals. Anim Reprod Sci. 2020:106316. https://doi.org/10.1016/j.anireprosci. 2020.106316.

57. Case A, Deaton A. Rising morbidity and mortality in midlife among white non-Hispanic Americans in the 21st century. Proc Natl Acad Sci USA 2015;112:15078-83.

58. Johnston LD, Miech RA, O'Malley PM, Bachman JG, Schulenberg JE, Patrick ME. Monitoring the Future national survey results on drug use 1975-2018: overview, key findings on adolescent drug use. Ann Arbor: Institute for Social Research, The University of Michigan; 2019.

59. Schulenberg JE, Johnston LD, O’Malley PM, Bachman JG, Miech RA, Patrick ME. Monitoring the Future national survey results on drug use, 1975-2018: Volume II, College students and adults ages 19-60. Ann Arbor: Institute for Social Research, The University of Michigan; 2019.

60. Barnard ND. Trends in food availability, 1909-2007. Am J Clin Nutr. 2010;91:1530S-6S.

61. Tran NL, Barraj LM, Bi X, Jack MM. Trends and patterns of caffeine consumption among US teenagers and young adults, NHANES 2003-2012. Food Chem Toxicol. 2016;94:227-42.

62. Stopka TJ, Amaravadi H, Kaplan AR, Hoh R, Bernson D, Chui $\mathrm{KKH}$, et al. Opioid overdose deaths and potentially inappropriate opioid prescribing practices (PIP): a spatial epidemiological study. Int J Drug Policy. 2019;68:37-45.

63. Kendler KS, Chen X, Dick D, Maes H, Gillespie N, Neale MC, et al. Recent advances in the genetic epidemiology and molecular genetics of substance use disorders. Nat Neurosci. 2012;15:181-9.
64. Sim MS, Soga T, Pandy V, Wu YS, Parhar IS, Mohamed Z. MicroRNA expression signature of methamphetamine use and addiction in the rat nucleus accumbens. Metab Brain Dis. 2017;32:1767-83.

65. Si Y, Song Z, Sun X, Wang JH. microRNA and mRNA profiles in nucleus accumbens underlying depression versus resilience in response to chronic stress. Am J Med Genet B Neuropsychiatr Genet. 2018;177:563-79.

66. Maldonado-Aviles JG, Guarnieri DJ, Zhu X, DiLeone RJ. Downregulation of miRNAs in the brain and development of dietinduced obesity. Int J Dev Neurosci. 2018;64:2-7.

67. Kim J, Im HI, Moon C. Intravenous morphine self-administration alters accumbal microRNA profiles in the mouse brain. Neural Regen Res. 2018;13:77-85.

68. Quinn RK, James MH, Hawkins GE, Brown AL, Heathcote A, Smith DW, et al. Temporally specific miRNA expression patterns in the dorsal and ventral striatum of addiction-prone rats. Addict Biol. 2018;23:631-42.

69. Volkow ND, Wise RA, Baler R. The dopamine motive system: implications for drug and food addiction. Nat Rev Neurosci. 2017;18:741-52.

70. Lennerz BS, Alsop DC, Holsen LM, Stern E, Rojas R, Ebbeling $\mathrm{CB}$, et al. Effects of dietary glycemic index on brain regions related to reward and craving in men. Am $\mathrm{J}$ Clin Nutr. 2013;98:641-7.

71. Lopez-Cortegano E, Caballero A. Inferring the nature of missing heritability in human traits using data from the GWAS catalog. Genetics 2019;212:891-904.

72. Wang K, Gaitsch H, Poon H, Cox NJ, Rzhetsky A. Classification of common human diseases derived from shared genetic and environmental determinants. Nat Genet. 2017;49:1319-25.

73. Elia J, Glessner JT, Wang K, Takahashi N, Shtir CJ, Hadley D, et al. Genome-wide copy number variation study associates metabotropic glutamate receptor gene networks with attention deficit hyperactivity disorder. Nat Genet. 2011;44:78-84.

74. Lee KW, Woon PS, Teo YY, Sim K. Genome wide association studies (GWAS) and copy number variation (CNV) studies of the major psychoses: what have we learnt? Neurosci Biobehav Rev. 2012;36:556-71.

75. Momen NC, Plana-Ripoll O, Agerbo E, Benros ME, Borglum AD, Christensen MK, et al. Association between mental disorders and subsequent medical conditions. N Engl J Med. 2020;382:1721-31. 